\title{
Prediction of the Aerothermodynamic Environment of the Huygens Probe
}

\author{
Brian R. Hollis* and Scott A. Striepe ${ }^{\dagger}$ \\ NASA Langley Research Center, Hampton, VA, 23681 \\ Michael J. Wright* \\ NASA Ames Research Center, Moffett Field 94035 \\ Deepak Bose $\mathrm{B}^{\S}$ \\ ELORET Corporation, Moffett Field, VA 94035 \\ Kenneth Sutton $^{* *}$ \\ National Institute of Aerospace, Hampton, VA 23666 \\ Naruhisa Takashima ${ }^{\dagger \dagger}$ \\ AMA Inc., Hampton, VA 23666
}

\begin{abstract}
An investigation of the aerothermodynamic environment of the Huygens entry probe has been conducted. A Monte Carlo simulation of the trajectory of the probe during entry into Titan's atmosphere was performed to identify a worst-case heating rate trajectory. Flowfield and radiation transport computations were performed at points along this trajectory to obtain convective and radiative heat-transfer distributions on the probe's heat shield. This investigation identified important physical and numerical factors, including atmospheric $\mathrm{CH}_{4}$ concentration, transition to turbulence, numerical diffusion modeling, and radiation modeling, which strongly influenced the aerothermodynamic environment.
\end{abstract}

\section{Nomenclature}

$M_{e} \quad=$ boundary-layer edge Mach number

$M_{\infty} \quad=\quad$ free stream Mach number

$p_{\infty} \quad=$ free stream pressure

$q_{\text {conv }}=$ convective heat transfer rate

$q_{\text {rad }}=$ radiative heat transfer rate

$R_{b} \quad=$ base (maximum) radius

$R_{c} \quad=$ corner radius

$R_{n} \quad=$ nose radius

$\operatorname{Re}_{\theta} \quad=$ Reynolds number based on boundary layer momentum thickness and edge conditions

$\operatorname{Re}_{\infty} \quad=$ free stream Reynolds Number

Sc $\quad=$ Schmidt number

$T_{\infty} \quad=$ free stream temperature

$U_{\infty} \quad=$ free stream velocity

$x=$ distance normal to symmetry axis in pitch plane

$\Gamma \quad=$ Goulard number

\footnotetext{
* Aerospace Engineer, Aerothermodynamics Branch, AIAA Senior Member

${ }^{\dagger}$ Aerospace Engineer, Exploration Systems Engineering Branch

* Senior Research Scientist, Reacting Flow Environments Branch, AIAA Senior Member

$\S$ Senior Research Scientist, AIAA Member

** Research Scientist, AIAA Fellow

${ }^{\dagger}$ Research Scientist, AIAA Senior Member
} 


$\begin{array}{ll}\phi & =\text { three-dimensional correction factor } \\ \kappa & =\text { atmospheric composition constant } \\ \theta & =\text { boundary-layer momentum thickness } \\ \rho_{\infty} & =\text { free stream density }\end{array}$

\section{Background}

The Cassini-Huygens project is a joint NASA-European Space Agency (ESA) mission to explore Saturn and its satellites, in particular the moon Titan. The NASA-built Cassini orbiter was designed to explore the Saturn system for at least 4 years, while the ESA-built Huygens probe was designed to land on Titan. The Cassini-Huygens spacecraft (Figure 1) was launched October 15, 1997 and arrived in Saturn orbit on July 01, 2004. The Huygens probe was released from Cassini on December 24, 2004 and successfully entered Titan's atmosphere and landed on its surface on January 14, 2005.

The Huygens probe (Figure 2), which is the subject of this work, consists of a heat shield/aerodynamic decelerator and an instrumentation module that contains the mission's scientific payload. The heat shield is a 2.700 $\mathrm{m}$ diameter, 60-deg sphere-cone configuration with an open back face. The nose radius is $1.250 \mathrm{~m}$ and the corner radius is $0.025 \mathrm{~m}$. For the purposes of the present study, wake flow computations were not performed and thus the geometry was modeled only to the shoulder.

Prior to the release of the Huygens probe from the Cassini spacecraft, the NASA Engineering and Safety Center (NESC) sponsored an independent technical assessment ${ }^{2}$ of the entry, descent and landing (EDL) performance of the probe. This assessment included vehicle aerodynamics, parachute deployment and loads, Titan atmospheric properties, trajectory simulation, thermal protection system (TPS) performance, and aerothermodynamic environments. The aerothermodynamic environments generated to support this assessment, which included convective (both laminar and turbulent) and radiative heat-transfer rates, are reported herein. Additional information on Huygens aerothermodynamics is presented in Reference 3.

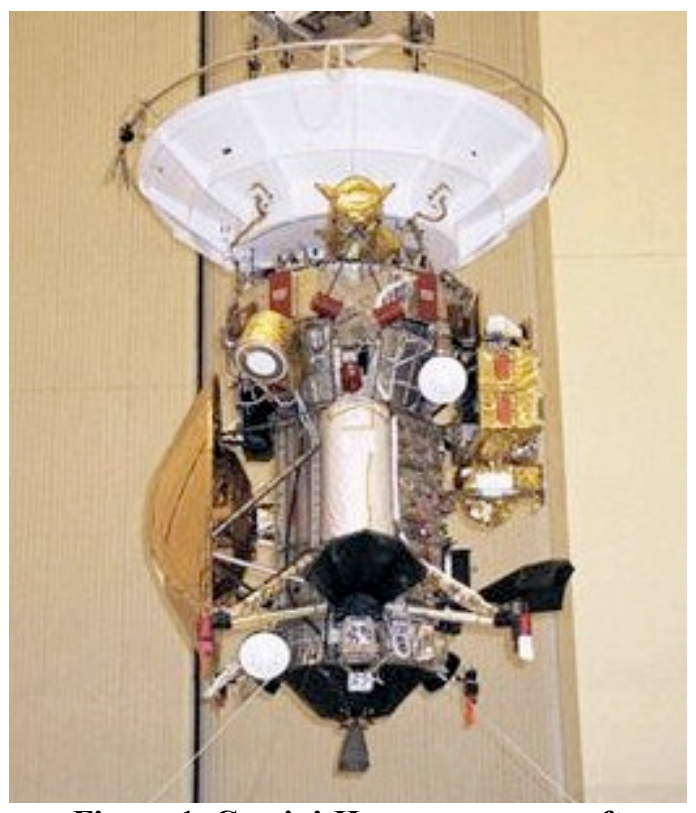

Figure 1. Cassini-Huygens spacecraft

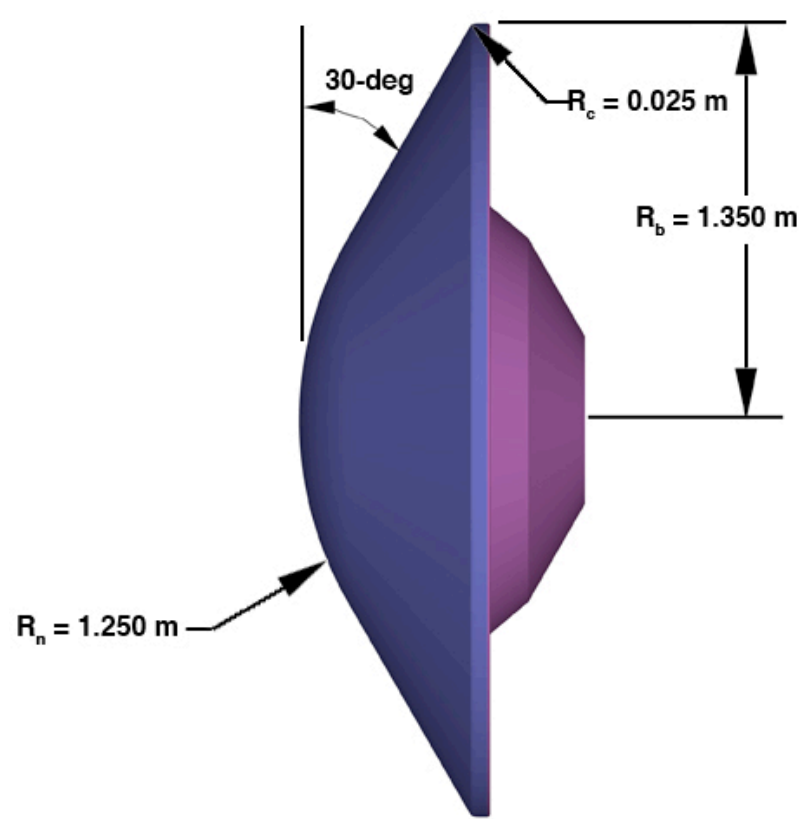

Figure 2. Huygens entry vehicle geometry

\section{Trajectory Analysis}

Simulations and analyses of the Huygens probe entry into Titan's atmosphere were conducted in order to generate trajectories on which to perform detailed flow field and radiation transport computations. The major components of this activity, which are detailed in subsequent sections, were atmospheric modeling, aerodynamic database generation, and simulation and Monte Carlo analysis of trajectories. A range of possible trajectories was 
generated based on dispersion of simulation parameters. The trajectory on which the maximum heat-transfer rate would occur was identified and computations were performed at selected points along it to determine the aerothermodynamic environment.

\section{A. Titan Atmospheric Composition}

The major component of Titan's atmosphere is $\mathrm{N}_{2}$, a small $\mathrm{CH}_{4}$ component is known to exist, and there may be some Ar. While other more complex compounds are also present, they exist only in trace amounts that are not relevant to entry vehicle analyses. At the time of this study, the exact proportions of the species were not known; one of the scientific goals of the Cassini-Huygens mission is to precisely determine Titan's atmospheric composition.

Atmospheric profiles were obtained from the TitanGRAM code ${ }^{4}$, which provided altitude-density-temperature data and ranges of dispersions. $\mathrm{N}_{2}$ mole fractions varied from $85 \%$ to $97 \%$ depending on dispersions. $\mathrm{CH}_{4}$ and $\mathrm{Ar}$ comprised the remainder of the atmosphere, with the proportions determined by user specification of the $\mathrm{CH}_{4}$ mole fraction, which, according to the most up-to-date information available from Cassini measurements, was expected to be in the range of $1 \%$ to $5 \%$. Version 1.0 of the Titan-GRAM atmospheric code was employed in this study, with updates to the code based on the available Cassini measurements of Titan's atmosphere (from July 3, 2004 and Nov. 15,2004 , designated as the T0 and TA atmospheric profiles).

\section{B. Huygens Aerodynamic Database}

A high-fidelity aerodynamic database was developed to support the simulations of the Huygens probe from the Titan atmospheric interface to parachute deployment. Because of the similarity in the forebody shape of Huygens to that of the Genesis Sample Return Capsule (SRC), the Genesis aerodynamic database was used as the foundation for the Huygens aerodynamic database. The Genesis aerodynamic database was constructed using data from engineering analysis tools, high-fidelity numerical analysis solutions (i.e., CFD), ground-based wind tunnel tests, and free-flight ballistic range tests. The details of the Genesis aerodynamic database are described by Desai ${ }^{5}$.

Although the Huygens probe and Genesis capsule have similar 60-degree sphere cone forebodies, the Huygens probe has a larger nose radius relative to the probe diameter. The difference in the nose radius resulted in an axial force coefficient value that was greater than that of the Genesis capsule throughout the Mach range. At the hypersonic continuum limit, that difference in the coefficient was $6.8 \%$. To account for the differences in the geometry between the Huygens probe and the Genesis SRC, the Genesis aerodynamic database was revised. Freemolecular and modified-Newtonian analyses were performed to anchor the rarefied and continuum aerodynamics, and for the supersonic/hypersonic flow regime, data from ballistic range free-flight tests ${ }^{6}$ of Huygens probe models were used to characterize the aerodynamics.

\section{Trajectory Simulation and Monte Carlo Analysis}

A six degree-of-freedom (6DOF) atmospheric entry and three degree-of-freedom (3DOF) parachute descent trajectory of the Huygens probe was simulated in POST2 (Program to Optimize Simulated Trajectories II) ${ }^{7}$. POST2 is a generalized point mass, discrete parameter targeting and optimization trajectory program and has the ability to simulate 3DOF and 6DOF trajectories for multiple vehicles in various flight regimes. POST2 also has the capability to include different atmosphere, aerodynamics, gravity, propulsion, parachute, and navigation system models, and Titan/Huygens-specific models were implemented for this study. POST2 has been used to simulate the entry trajectories for previous NASA missions (e.g. Mars Pathfinder ${ }^{8}$, Mars Exploration Rover ${ }^{9}$, Genesis ${ }^{10}$ ) as well as numerous system studies (e.g. aerocapture at Neptune ${ }^{11}$ and $\operatorname{Titan}^{12}$ ).

The POST2 simulation method was used in a Monte Carlo analysis of the Huygens probe entry, descent, and impact at Titan. The Monte Carlo technique involves the variation of key simulation parameters (e.g. initial orientation, aerodynamic coefficients, atmospheric parameters) to encompass the levels of uncertainty in these quantities. Aeroheating parameters (laminar and turbulent convective heating rates and radiative heating rates at the stagnation point) generated from high-fidelity computational analyses performed along the POST2-generated trajectories were incorporated into successive Monte Carlo simulations through simplified time-history curve-fits in

order to refine subsequent trajectory analyses. Several thousand runs were made with random variations of parameters, and statistics of the resulting outputs were analyzed to identify maximum heat-rate trajectories for further detailed computational analyses, as described below. This process was repeated for several iterations to produce the final trajectory on which the aeroheating computations presented herein were performed. The worstcase trajectory for the integrated heat load was also identified through this Monte Carlo simulation; however, the difference between these max heat-rate and max heat-load trajectories was small for Huygens, and so only the 
maximum heat-rate trajectory will be discussed. It is expected that a trajectory reconstruction will be performed using mission data when it becomes available in order to determine the actual conditions that the probe encountered.

Aerothermodynamic computations were performed for several points along the maximum heating rate trajectory. The free stream conditions for these points are listed in Table 1 and plotted in Figure 3. The peak convective heating rate occurs at $\mathrm{t}=189 \mathrm{~s}$ on this trajectory. In addition to the listed cases with the default species concentrations, cases were also run with the $\mathrm{CH}_{4}$ mole fraction varied by $\pm 30 \%$ (with the $\mathrm{N}_{2}$ and Ar mole fractions varied accordingly to retain the same molecular weight as the baseline condition) in order to investigate the influence of $\mathrm{CH}_{4}$ on the aerothermodynamic environment. This influence is primarily a function of the number of $\mathrm{C}$ atoms available to form $\mathrm{CN}$ (which is the major contributor to radiation for flight in Titan's atmosphere) through reactions in the shock region.

Table 1. Free Stream Conditions on Maximum Heat-Rate Trajectory

\begin{tabular}{ccccccccccc}
\hline $\begin{array}{c}\mathbf{t} \\
(\mathbf{s e c})\end{array}$ & $\begin{array}{c}\mathbf{h} \\
\mathbf{( k m})\end{array}$ & $\begin{array}{c}\mathbf{U}_{\infty} \\
(\mathbf{m} / \mathbf{s})\end{array}$ & $\begin{array}{c}\boldsymbol{\rho}_{\infty} \\
\mathbf{( k m} / \mathbf{s})\end{array}$ & $\begin{array}{c}\mathbf{p}_{\infty} \\
\mathbf{( P a )}\end{array}$ & $\begin{array}{c}\mathbf{T}_{\infty} \\
\mathbf{( K )}\end{array}$ & $\mathbf{M}_{\infty}$ & $\begin{array}{c}\mathbf{R e}_{\infty} \\
(\mathbf{1} / \mathbf{m})\end{array}$ & $\begin{array}{c}\mathbf{N}_{\mathbf{2}} \\
(\mathbf{m o l e} \mathbf{\%})\end{array}$ & $\begin{array}{c}\mathbf{C H}_{\mathbf{4}} \\
(\mathbf{m o l e} \%)\end{array}$ & $\begin{array}{c}\mathbf{A r} \\
(\mathbf{m o l e} \%)\end{array}$ \\
\hline 151.02 & 460.2 & 6166.6 & $6.22 \mathrm{E}-06$ & $3.12 \mathrm{E}-01$ & 150.8 & 23.93 & $3.71 \mathrm{E}+03$ & 0.9706 & 0.0230 & 0.0064 \\
169.02 & 367.9 & 6048.8 & $3.64 \mathrm{E}-05$ & $2.12 \mathrm{E}+00$ & 171.3 & 22.03 & $1.90 \mathrm{E}+04$ & 0.9701 & 0.0230 & 0.0070 \\
177.02 & 328.5 & 5886.3 & $7.20 \mathrm{E}-05$ & $4.69 \mathrm{E}+00$ & 175.8 & 21.16 & $3.57 \mathrm{E}+04$ & 0.9699 & 0.0230 & 0.0071 \\
185.02 & 291.1 & 5489.6 & $1.83 \mathrm{E}-04$ & $1.01 \mathrm{E}+01$ & 177.0 & 19.67 & $8.42 \mathrm{E}+04$ & 0.9699 & 0.0230 & 0.0071 \\
189.17 & 273.2 & 5126.3 & $2.96 \mathrm{E}-04$ & $1.46 \mathrm{E}+01$ & 176.6 & 18.38 & $1.27 \mathrm{E}+05$ & 0.9699 & 0.0230 & 0.0071 \\
193.02 & 257.8 & 4705.2 & $3.79 \mathrm{E}-04$ & $2.02 \mathrm{E}+01$ & 175.8 & 16.91 & $1.50 \mathrm{E}+05$ & 0.9699 & 0.0230 & 0.0071 \\
201.02 & 230.5 & 3660.4 & $7.43 \mathrm{E}-04$ & $3.64 \mathrm{E}+01$ & 173.4 & 13.25 & $2.32 \mathrm{E}+05$ & 0.9699 & 0.0230 & 0.0071 \\
209.02 & 209.7 & 2693.7 & $1.11 \mathrm{E}-03$ & $5.78 \mathrm{E}+01$ & 170.9 & 9.82 & $2.59 \mathrm{E}+05$ & 0.9699 & 0.0230 & 0.0071 \\
225.02 & 184.1 & 1337.7 & $2.24 \mathrm{E}-03$ & $1.05 \mathrm{E}+02$ & 167.1 & 4.93 & $2.64 \mathrm{E}+05$ & 0.9699 & 0.0230 & 0.0071 \\
\hline
\end{tabular}

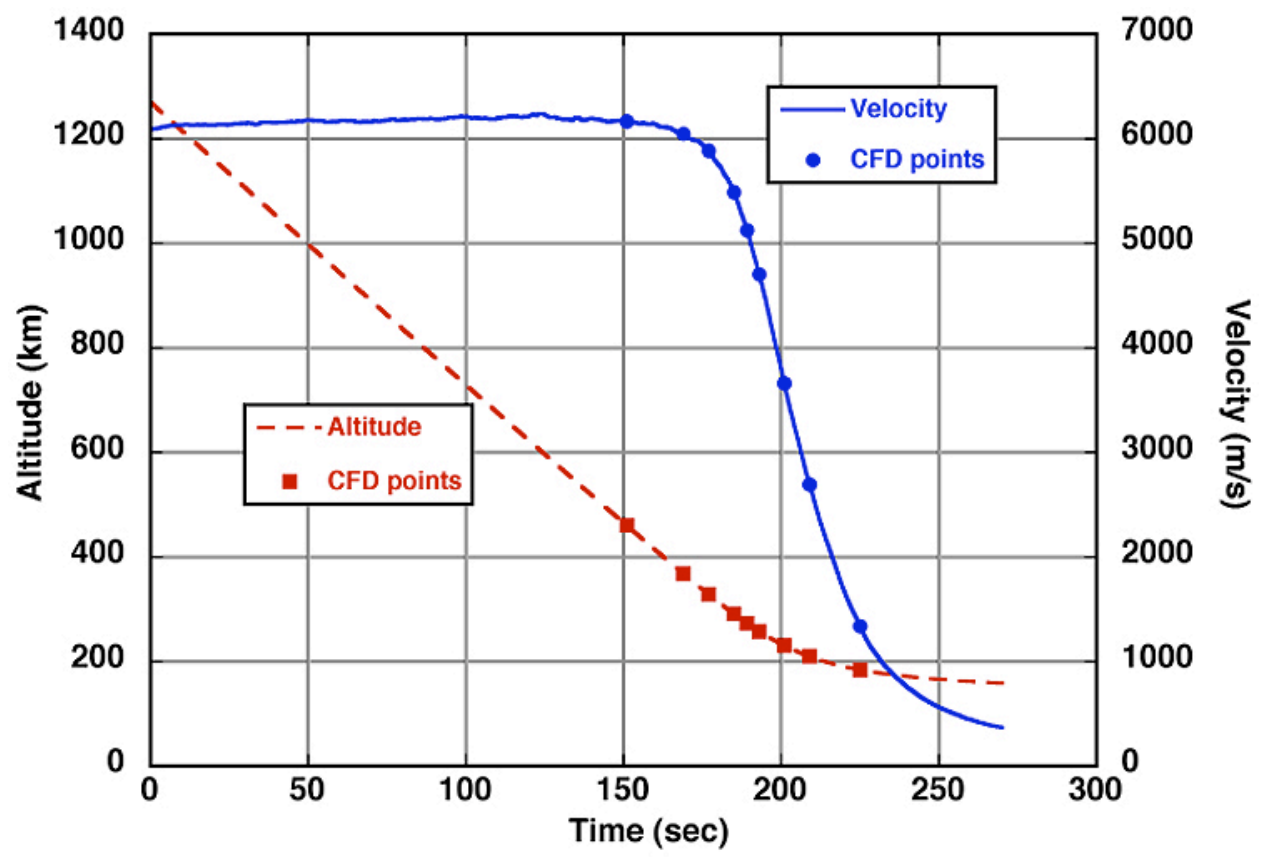

Figure 3. Velocity and altitude vs. time along maximum heating-rate trajectory

\section{Flow-Field and Radiation Transport Methods}

Because there is relatively little experience on which to base estimates for the fidelity of computational tools and methods for Titan atmospheric entry problems (as opposed to Earth or Mars), independent analyses were performed using two separate tool sets: the LAURA flow-field solver with the RADEQUIL radiation transport code, and the DPLR flow-field solver with the NEQAIR96 radiation transport code. The current Huygens probe analysis relied heavily on upgrades and modifications to these tools resulting from a recent system study ${ }^{12,13,14,15}$ of aerocapture at Titan. 


\section{A. LAURA and DPLR Flow Field Codes}

Flow field computations were performed using the LAURA ${ }^{16,17}$ (Langley Aerothermodynamic Upwind Relaxation Algorithm) and DPLR ${ }^{18}$ (Data Parallel Line Relaxation) codes. Both codes are structured, threedimensional, finite-volume solvers for the Navier-Stokes equations in hypersonic flow fields. In the LAURA code, inviscid fluxes are computed using the Roe second-order flux-splitting ${ }^{19}$ with the Harten entropy fix ${ }^{20}$ and the Yee symmetric total-variation diminishing limiter ${ }^{21}$. In DPLR, a modified Steger-Warming flux-vector splitting ${ }^{22}$ with MUSCL extrapolation to third order via a "minmod" limiter ${ }^{23}$ is employed.

Both codes incorporate chemical non-equilibrium and vibrational non-equilibrium kinetic models. For Titan's atmosphere, forward chemical reaction rates were taken from the 21 -species $\left(\mathrm{Ar}, \mathrm{C}, \mathrm{CH}, \mathrm{CH}_{2}, \mathrm{CH}_{3}, \mathrm{CH}_{4}, \mathrm{CN}, \mathrm{C}_{2}, \mathrm{H}\right.$, $\mathrm{HCN}, \mathrm{H}_{2}, \mathrm{~N}, \mathrm{NH}, \mathrm{N}_{2}, \mathrm{Ar}^{+}, \mathrm{C}^{+}, \mathrm{CN}^{+}, \mathrm{H}^{+}, \mathrm{N}^{+}, \mathrm{N}_{2}{ }^{+}$, e), 35-reaction model developed by Gökçen ${ }^{24}$ (although the ionized species and ionization reactions were omitted for the Huygens trajectories), and vibrational non-equilibrium is based on the Park two-temperature model ${ }^{25}$. Reverse reaction rates are determined from the definition of the equilibrium constant, which is evaluated using the Gibbs free energy computed from McBride's thermodynamic curve fits ${ }^{26}$.

\section{B. RADEQUIL AND NEQAIR96 Radiation Transport Codes}

Radiative heating rates were determined using the RADEQUIL ${ }^{27}$ and NEQAIR96 ${ }^{28}$ codes. These codes are used to compute emission and absorption of radiation from excited species. The populations of the excited states of the species are based on Boltzmann equilibrium distributions at the conditions determined from the LAURA or DPLR flow field computations. Radiation transport is then computed along selected lines-of-sight from the shock wave to the surface using the one-dimensional tangent slab assumption. With respect to this Boltzmann distribution assumption, it should be noted that recent experimental results ${ }^{29}$ indicate that the $\mathrm{CN}$ excited state populations do not follow a Boltzmann distribution at test conditions approximating Huygens entry. Thus, the radiative heating predictions presented herein, which are based on the Boltzmann assumption, may be overly conservative.

Radiation computations in the RADEQUIL code are performed using a grouping of atomic line transitions at similar frequencies and a smeared band approximation of frequency-integrated molecular rotational/vibrational transitions. In the NEQAIR96 code, line-by-line computations are performed for atomic transitions and molecular transitions are computed for a large number of frequency points in order to capture all spectral details.

Coupling between energy loss to the free stream via radiation and the flow field predictions was performed using an approximate technique developed by Tauber $^{30}$ to account for this radiative cooling of the flow field and the accompanying reduction in radiative heating levels. In this approximation, the ratio of coupled to uncoupled radiative heating rates is given by:

(1) $\frac{q_{\text {rad }}^{\text {coup }}}{q_{\text {rad }}^{\text {uncoup }}}=\frac{1}{1+\kappa \Gamma^{0.7}}$

In equation (1), $\Gamma$ is the Goulard number ${ }^{31}$ defined by:

(2) $\Gamma=\frac{2 q_{\text {rad }}^{\text {uncoup }}}{\frac{1}{2} \rho_{\infty} U_{\infty}^{3}}$

In equation (2), $\kappa$ is an empirical constant that is a function of atmospheric composition. In Ref. 31 , a value of 3.0 for this constant was reported. However, an investigation was also conducted to determine a more accurate value for Titan conditions using the coupled technique developed by Wright $\mathrm{t}^{32}$ for the special case of the opticallythin shock layer. It was found that a value of $\kappa=2.0$ provided a better match with the optically-thin coupled method, and so approximate coupling results presented herein are based on this value.

An additional correction factor given by equation (3) to the tangent-slab assumption to account for threedimensional effects (shock-layer curvature and decrease in radiation away from the stagnation point) was also applied.

(3) $q_{3 D}=\phi q_{1 D}$ 
The correction factor $\phi$ was based on the view factor analysis developed by Bose ${ }^{33}$ and was set to 0.75 for the stagnation-point on the Huygens geometry. Along the conical flank of the vehicle, a value of 0.90 was used.

\section{Boundary Conditions and Solution Procedure}

For all flow field computations, a radiative-equilibrium wall temperature boundary condition with an emissivity of 0.90 was employed. In order to obtain conservative heating results a "super-catalytic" boundary condition (recombination to free-stream mass fractions) was imposed at the wall for the LAURA computations, while the DPLR boundary condition was full recombination of $\mathrm{N}_{2}$ and $\mathrm{H}_{2}$. Since $\mathrm{N}_{2}$ is the primary component of the atmosphere, the different boundary conditions have a small effect $(<5 \%)$ on the computed convective heating rates. As the nominal angle-of-attack for the Huygens probe was 0-deg, all computations were performed in axisymmetric mode.

The flow-field species concentrations and thermodynamic properties from the computations were used as inputs to the radiation transport codes. Radiative transport was then computed using the one-dimensional tangent-slab approximation to obtain uncoupled radiative heating rates. The correction given in equation (1) for energy loss to the free stream was then applied to the computed radiative heating rates to obtain approximate coupled radiative heating rates.

\section{Aerothermodynamic Environments}

The aerothermodynamic environment of the Huygens probe is discussed in this section. Radiative and convective heating distributions are presented for points along the maximum heat-rate trajectory. Numerical and physical factors that influence the heating rates are examined.

\section{A. Diffusion Modeling Effects on Convective Heating}

An important phenomenon noted in this study was the effect of the diffusion model employed in the computations. Both LAURA and DPLR employ multi-component diffusion models, which are referred to as the approximate, corrected multi-diffusion mode ${ }^{34}$ in LAURA and the self-consistent effective binary diffusion (SCEBD) model $^{35}$ in DPLR. Both codes do, however, retain simpler models based on the approximation of binary diffusion with a constant Schmidt number. For environments such as flight through Earth's atmosphere in which all the major species (e.g. $\mathrm{N}_{2}, \mathrm{O}_{2}, \mathrm{~N}, \mathrm{O}$ ) have roughly similar properties, this approximation may provide reasonably accurate results. However, the presence of $\mathrm{H}$ and $\mathrm{H}_{2}$ in the flow-field (which results from $\mathrm{CH}_{4}$ dissociation), even in limited quantities, renders this approximation invalid. As shown in Figure 4 and Figure 5 (peak convective heating on the max heat-rate trajectory for LAURA and DPLR predictions), the constant Schmidt number method resulted in significant under-prediction of the heating levels for both laminar and turbulent flows. Note that for comparison, results are also shown for the exact Stefan-Maxwell model for multi-component diffusion, a close match with which was obtained using both multi-component diffusion models. While diffusion modeling had significant effects on convective heating, radiative heating predictions for these cases differed by less than $1 \%$. The greater influence for convection was due to the fact that the diffusion model primarily affects flow in the boundary layer, on which convective heating rates depend, whereas radiative heating is due primarily to the high-temperature shock-layer region, which is not greatly influenced by the diffusion model. 


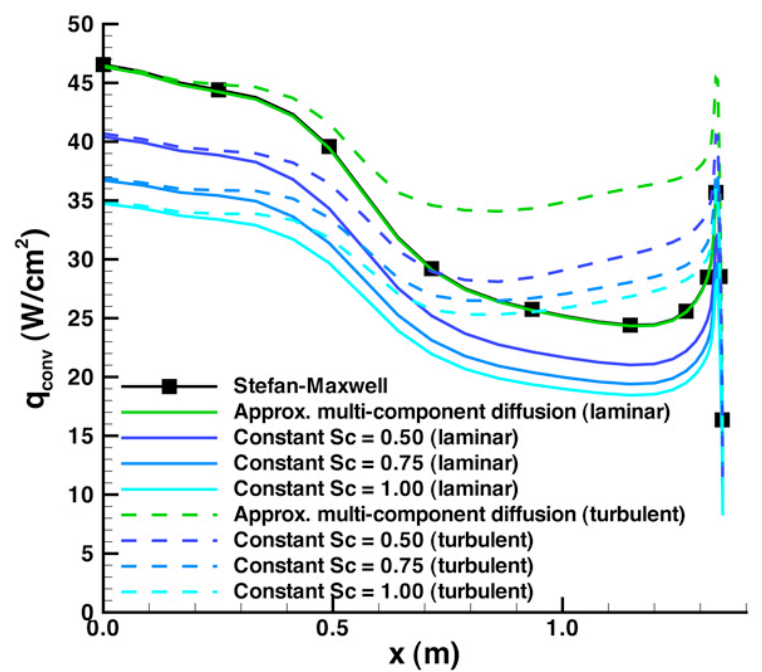

Figure 4. Diffusion modeling effects on convective heating, LAURA solutions at $t=189$ sec

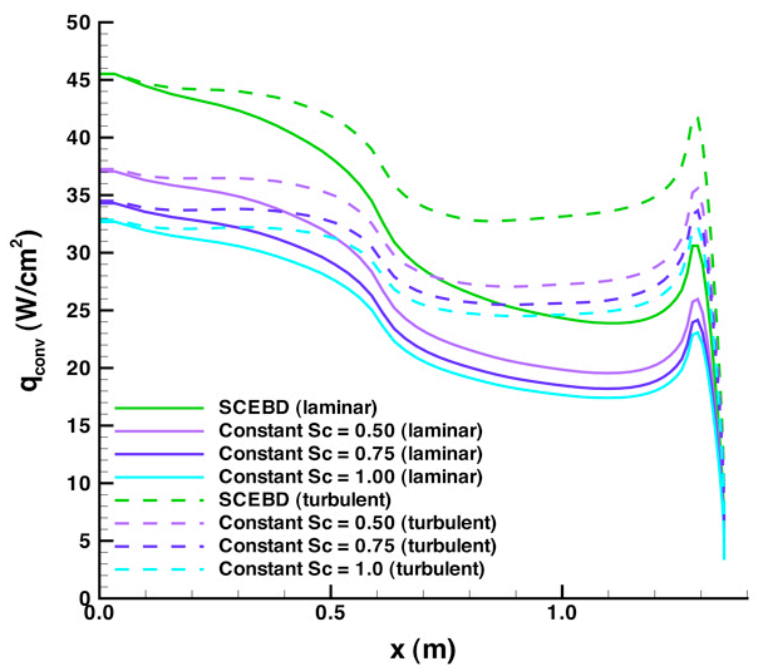

Figure 5. Diffusion modeling effects on convective heating, DPLR solutions at $t=189 \mathrm{sec}$

\section{B. $\mathrm{CH}_{4}$ Concentration Effects on Radiative Heating}

At the time during which this work was performed, the concentration of $\mathrm{CH}_{4}$ in Titan's atmosphere was not known precisely. A best estimate for the $\mathrm{CH}_{4}$ mole fraction of $2.3 \%$ was employed in the analysis, and computations were also performed with $\mathrm{CH}_{4}$ mole fractions varied by $\pm 30 \%$ from the default in order to determine its influence on the aerothermodynamic environment. Both convective and radiative heating levels were found to increase as the amount of $\mathrm{CH}_{4}$ in the atmosphere was increased. $\mathrm{CH}_{4}$ concentration effects on convective (laminar and turbulent) heating are shown in Figure 6; LAURA results are shown, DPLR results were in close agreement. $\mathrm{CH}_{4}$ concentration effects on radiative heating (uncoupled and approximate coupled) are shown in Figure 7 for LAURA-RADEQUIL computations; DPRL-NEQAIR96 computations showed the same trends but with some differences in magnitude of the effects. The influence of $\mathrm{CH}_{4}$ concentration on radiative heating rates was much greater than on convective heating because it controls the amount of $\mathrm{CN}$ (which is the primary radiating specie) that can be formed in the flow field.

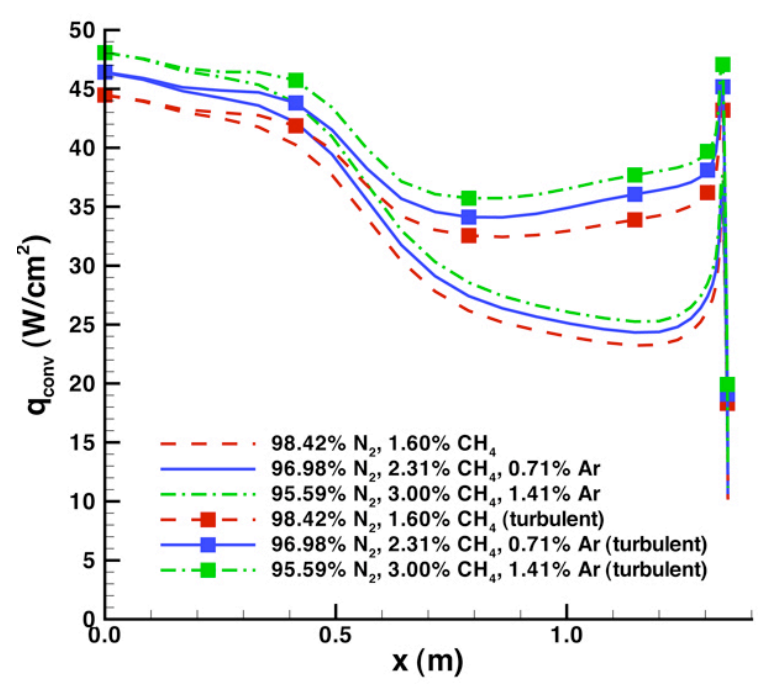

Figure 6. $\mathrm{CH}_{4}$ concentration effects on convective heating, LAURA predictions for $t=189$ sec on $\max$ heat-rate trajectory

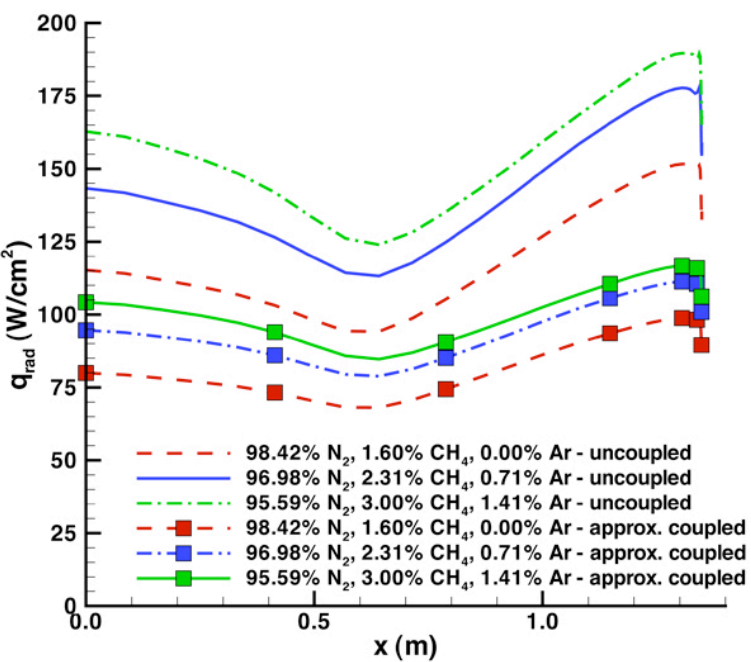

Figure 7. $\mathrm{CH}_{4}$ concentration effects on radiative heating, RADEQUIL predictions for $t=189 \mathrm{sec}$ on max heat-rate trajectory 


\section{Ionization effects on Heating}

For Huygens entry conditions at Titan, flow-field temperatures were too low for significant ionization to occur. A single check-case computed with ionization at the peak heating point $(t=189 \mathrm{~s})$ showed that the convective and radiative heating rates differed by less than $1 \%$ from those computed without ionization; therefore ionization was omitted from all other computations.

\section{Transition to Turbulence}

Transition to turbulence in hypersonic flows is difficult to predict, especially for an entry vehicle such as the Huygens probe that has steps and gaps between its heat-shield tiles and that will experience ablation. Transition onset is commonly defined in terms of local surface/flow-field conditions through the parameter $\mathrm{Re}_{\theta} / \mathrm{M}_{\mathrm{e}}$ (the ratio of the Reynolds number based on boundary-layer momentum thickness and edge conditions to the boundary-layer edge Mach number). Values of this parameter cited in the literature vary widely. In a recent transition study ${ }^{36}$ on a similar 70-deg sphere-cone entry vehicle configuration, $\mathrm{Re}_{\theta} / \mathrm{M}_{\mathrm{e}}$ values between 200 and 500 were measured in several different experimental facilities. For the purpose of this study, a value of 150 was selected in the hope that this would provide a conservative transition onset criterion. As shown in Figure 8, the predicted values for $\operatorname{Re}_{\theta} / \mathrm{M}_{\mathrm{e}}$ exceeded 150 along the flank of the cone by the time of peak heating. However, as will be shown subsequently, even though a conservative transition criterion was applied, the predicted turbulent heating levels along the cone did not exceed the stagnation-point level

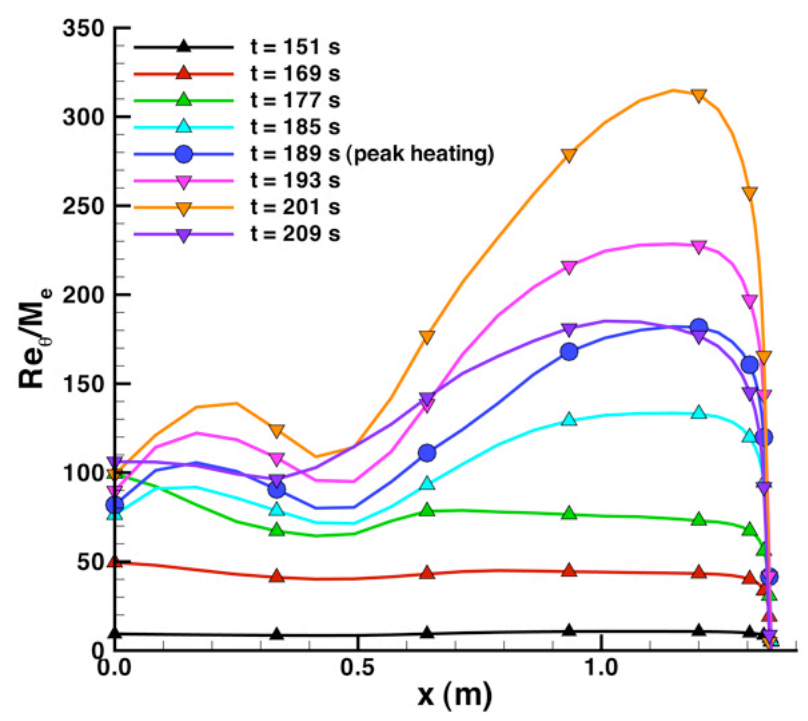

Figure 8. $\mathrm{Re}_{\theta} / \mathrm{M}_{\mathrm{e}}$ distributions at each trajectory point

\section{E. Convective and Radiative Heating Distributions}

Convective (both laminar and turbulent) and radiative heating distributions generated using LAURA and RADEQUIL along the trajectory are shown in Figure 9 and Figure 10, and distributions generated using DPLR and NEQAIR96 are shown in Figure 11 and Figure 12. Note that the radiative results shown in the figures are the uncoupled values, which were substantially higher than the approximate coupled values, as will be shown subsequently. The uncoupled values are shown in these figures in order to simplify comparisons between the results of the two radiation transport codes.

A comparison of laminar and turbulent convective distributions at peak heating is shown in Figure 13. Close agreement was obtained everywhere on the body except at the corners. The differences here were due to the fact that when the study began, information on the Huygens corner radius was not available, and the grid for the DPLR computations was generated using a larger radius than that for the LAURA computations.

A comparison of uncoupled radiative heating distributions at peak heating is shown in Figure 14. Much larger differences were noted in these radiative distributions than in the convective distributions. The reason for these 
differences has not yet been identified, however it has been noted that the NEQAIR96 code predicts more radiation absorption in the flow-field, leading to lower radiative heating at the surface, than does the RADEQUIL code.

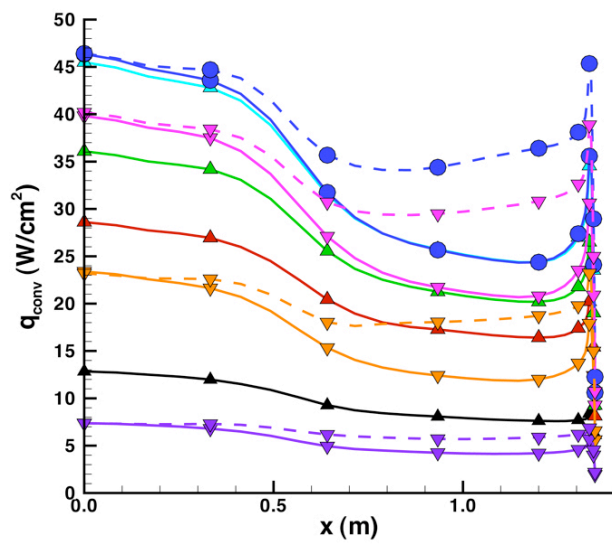

Figure 9. Laminar and turbulent convective heating distributions computed using LAURA

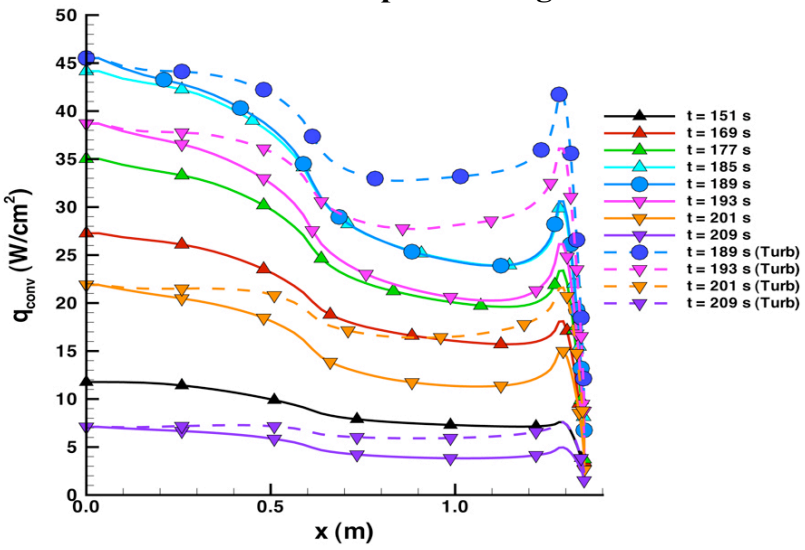

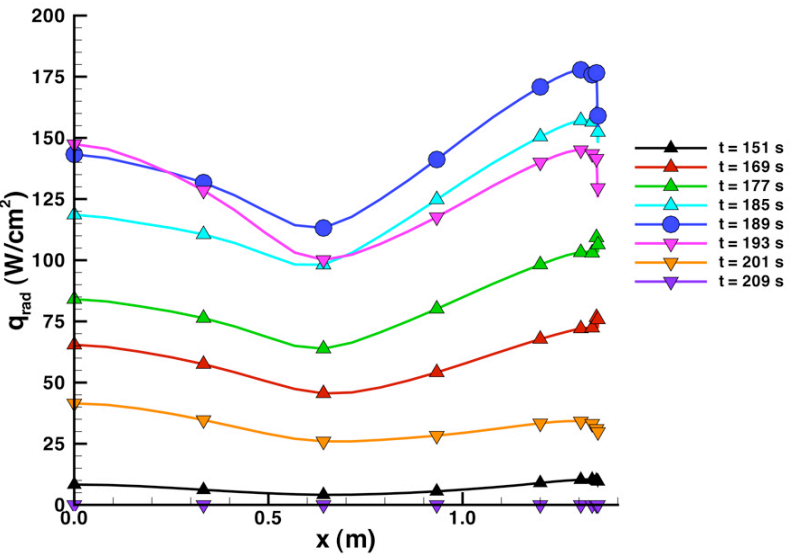

Figure 10. Uncoupled radiative heating distributions computed from LAURA inputs using RADEQUIL

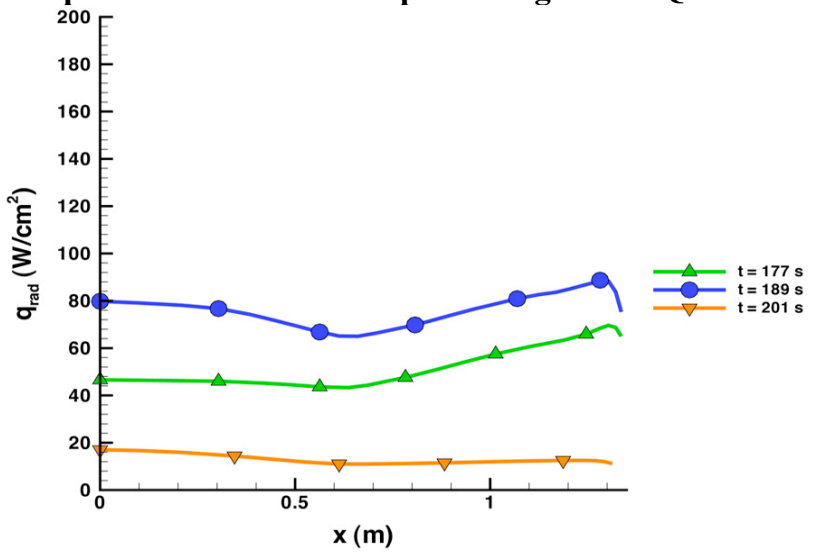

Figure 11. Laminar and turbulent convective heating Figure 12. Uncoupled radiative heating distributions distributions computed using DPLR computed from DPLR inputs using NEQAIR96

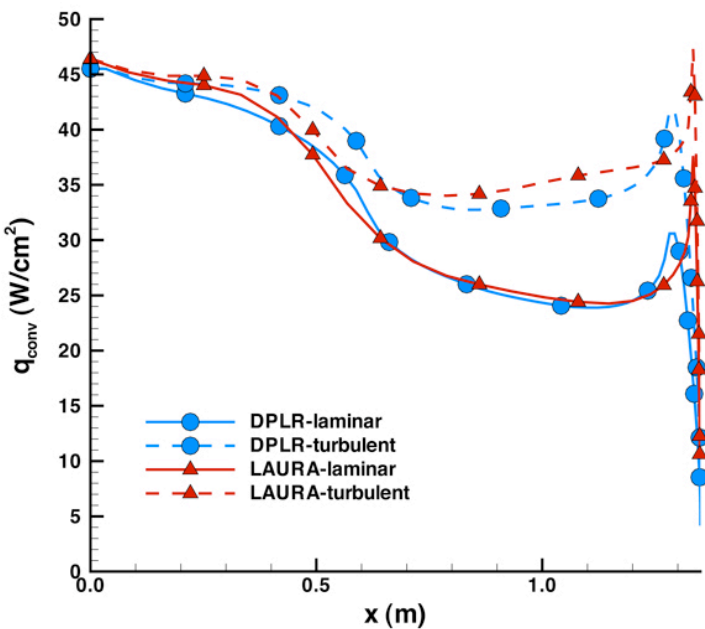

Figure 13. Comparison of LAURA and DPLR convective heating rates at $t=189 \mathrm{sec}$

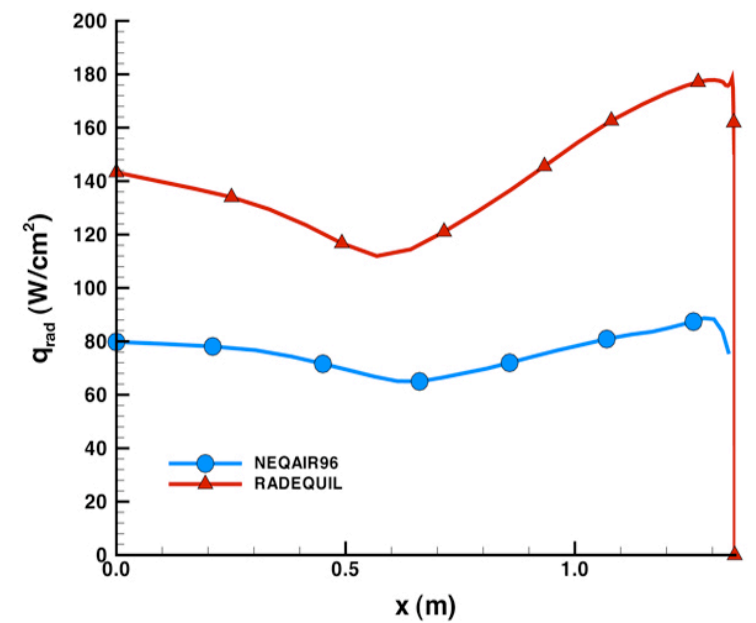

Figure 14. Comparison of RADEQUIL and NEQAIR96 radiative heating rates at $t=189 \mathrm{sec}$

9

American Institute of Aeronautics and Astronautics 


\section{F. Heating-Times Histories}

Heating-time history data for two locations on the heat shield, the stagnation point and a point just ahead of the shoulder $(\mathrm{x}=1.25 \mathrm{~m})$, are listed in Table 2 and Table 3 and plotted in Figure 15 and Figure 16, respectively. Results are presented for both LAURA-RADEQUIL and DPLR-NEQAIR96 computations. The total (radiative + convective) heating was computed in three different ways: as the sum of the convective and uncoupled radiative rates; as the sum of the convective and coupled radiative rates; and as the sum of the convective rates plus the coupled radiative rates times the three-dimensional correction factor. In these totals, the convective rate at the shoulder point was taken as the turbulent value for times after $185 \mathrm{sec}$. Radiative cooling due to flow-field coupling was found to reduce the radiative heating rates by approximately $15 \%$ to $50 \%$ depending on the trajectory point. The highest predicted total heating at the stagnation point (including coupling and three-dimensional corrections to radiative heating) was $117 \mathrm{~W} / \mathrm{cm}^{2}$ from the LAURA-RADEQUIL computations and $92 \mathrm{~W} / \mathrm{cm}^{2}$ from the DPLR/NEQAIR96 computations. Because of the radiative contribution to the heating environment, the highest heating on the body was not at the stagnation point, but instead was just ahead of the shoulder, where the predicted levels were $120 \mathrm{~W} / \mathrm{cm}^{2}$ and $93 \mathrm{~W} / \mathrm{cm}^{2}$, respectively. Very close agreement was observed between the LAURA and DPLR convective results, however, for radiative heating, the NEQAIR96 predictions were from $40 \%$ to $60 \%$ lower than the RADEQUIL predictions depending on the trajectory point.

The time histories of the convective and radiative rates were provided to the NESC independent technical assessment team. Because of the short deadlines set for this assessment, the reasons for significant differences between the radiative heating levels generated by the two different codes were not resolved, and the final radiative heating levels were taken to be the average of the two sets of results. These data were curve-fitted vs. time and used as inputs to thermal modeling analysis of the vehicle's TPS that was performed by ESA. The integrated heat-loads and material temperatures resulting from this analysis were determined by ESA and the NASA-NESC team to be within acceptable limits to allow for release of the Huygens probe into Titan's atmosphere.

Table 2. Heating rates at stagnation point

\begin{tabular}{|c|c|c|c|c|c|c|c|}
\hline Time (sec) & $\begin{array}{c}\text { Laminar } \\
\text { convective } \\
\left(W / \mathbf{c m}^{2}\right)\end{array}$ & $\begin{array}{c}\text { Turbulent } \\
\text { convective } \\
\left(\mathbf{W} / \mathbf{c m}^{2}\right)\end{array}$ & $\begin{array}{c}\text { Uncoupled } \\
\text { radiative } \\
\left(W / \mathbf{c m}^{2}\right)\end{array}$ & $\begin{array}{l}\text { Coupled } \\
\text { radiative } \\
\left(\mathbf{W} / \mathbf{c m}^{2}\right)\end{array}$ & $\begin{array}{c}\text { Convective + } \\
\text { uncoupled } \\
\text { radiative } \\
\left(\mathbf{W} / \mathbf{c m}^{2}\right)\end{array}$ & $\begin{array}{c}\text { Convective + } \\
\text { coupled } \\
\text { radiative } \\
\left(\mathbf{W} / \mathbf{c m}^{2}\right)\end{array}$ & $\begin{array}{c}\text { Convective }+ \\
\phi \times(\text { coupled } \\
\text { radiative }) \\
\left(W / \mathrm{cm}^{2}\right)\end{array}$ \\
\hline 151 & 12.8 & NA & 8.3 & 4.9 & 21.1 & 17.7 & 16.4 \\
\hline 169 & 28.6 & NA & 65.3 & 34.2 & 93.9 & 62.8 & 54.3 \\
\hline 177 & 36.0 & NA & 84.0 & 49.0 & 120.0 & 85.0 & 72.8 \\
\hline 189 & 46.3 & NA & 143.1 & 94.5 & 189.4 & 140.8 & 117.2 \\
\hline 193 & 39.8 & NA & 147.2 & 96.3 & 187.4 & 136.1 & 112.0 \\
\hline 201 & 23.4 & NA & 41.4 & 33.6 & 64.8 & 57.0 & 48.6 \\
\hline 209 & 7.4 & NA & 0.0 & 0.0 & 7.4 & 7.4 & 7.4 \\
\hline \multicolumn{8}{|c|}{ DPLR + NEQAIR96 } \\
\hline 151 & 11.8 & NA & 4.7 & 3.2 & 16.5 & 15.0 & 14.2 \\
\hline 169 & 27.3 & NA & 38.4 & 23.6 & 65.7 & 50.9 & 45.0 \\
\hline 177 & 35.0 & NA & 52.5 & 34.7 & 87.5 & 69.7 & 61.0 \\
\hline 189 & 45.5 & NA & 81.5 & 60.5 & 127.0 & 106.0 & 90.9 \\
\hline 193 & 38.7 & NA & 72.1 & 54.6 & 110.8 & 93.3 & 80.0 \\
\hline 201 & 21.9 & NA & 17.0 & 15.1 & 38.9 & 37.0 & 33.3 \\
\hline 209 & 7.1 & NA & 0.5 & 0.5 & 7.6 & 7.6 & 7.5 \\
\hline
\end{tabular}

Table 3. Heating rates ahead of shoulder $(x=1.25 \mathrm{~m})$

\begin{tabular}{|c|c|c|c|c|c|c|c|}
\hline Time (sec) & $\begin{array}{c}\text { Laminar } \\
\text { convective } \\
\left(\mathbf{W} / \mathbf{c m}^{2}\right)\end{array}$ & $\begin{array}{c}\text { Turbulent } \\
\text { convective } \\
\left(\mathbf{W} / \mathbf{c m}^{2}\right)\end{array}$ & $\begin{array}{c}\text { Uncoupled } \\
\text { radiative } \\
\left(\mathrm{W} / \mathrm{cm}^{2}\right)\end{array}$ & $\begin{array}{c}\text { Coupled } \\
\text { radiative } \\
\left(W / \mathbf{c m}^{2}\right)\end{array}$ & $\begin{array}{c}\text { Convective + } \\
\text { uncoupled } \\
\text { radiative } \\
\left(\mathbf{W} / \mathrm{cm}^{2}\right)\end{array}$ & $\begin{array}{c}\text { Convective }+ \\
\text { coupled } \\
\text { radiative } \\
\left(\mathbf{W} / \mathbf{c m}^{2}\right) \\
\end{array}$ & $\begin{array}{c}\text { Convective }+ \\
\phi \times(\text { coupled } \\
\text { radiative }) \\
\left(W / \mathrm{cm}^{2}\right)\end{array}$ \\
\hline 151 & 7.60 & NA & 9.7 & 5.4 & 17.3 & 13.0 & 12.5 \\
\hline 169 & 16.50 & NA & 70.0 & 35.8 & 86.5 & 52.3 & 48.7 \\
\hline 177 & 20.40 & NA & 101.1 & 55.8 & 121.5 & 76.2 & 70.6 \\
\hline
\end{tabular}

10

American Institute of Aeronautics and Astronautics 


\begin{tabular}{|c|c|c|c|c|c|c|c|}
\hline Time (sec) & $\begin{array}{c}\text { Laminar } \\
\text { convective } \\
\left(\mathbf{W} / \mathrm{cm}^{2}\right)\end{array}$ & $\begin{array}{c}\text { Turbulent } \\
\text { convective } \\
\left(\mathbf{W} / \mathbf{c m}^{2}\right)\end{array}$ & $\begin{array}{l}\text { Uncoupled } \\
\text { radiative } \\
\left(W / \mathrm{cm}^{2}\right)\end{array}$ & $\begin{array}{c}\text { Coupled } \\
\text { radiative } \\
\left(W / \mathbf{c m}^{2}\right)\end{array}$ & $\begin{array}{c}\text { Convective }+ \\
\text { uncoupled } \\
\text { radiative } \\
\left(W / \mathbf{c m}^{2}\right)\end{array}$ & $\begin{array}{c}\text { Convective }+ \\
\text { coupled } \\
\text { radiative } \\
\left(W / \mathbf{c m}^{2}\right)\end{array}$ & $\begin{array}{c}\text { Convective }+ \\
\phi \times(\text { coupled } \\
\text { radiative }) \\
\left(\mathbf{W} / \mathrm{cm}^{2}\right)\end{array}$ \\
\hline 185 & 24.70 & NA & 154.3 & 93.1 & 179.0 & 117.8 & 108.5 \\
\hline 189 & 24.80 & 36.7 & 175.0 & 110.0 & 196.2 & 131.2 & 120.2 \\
\hline 193 & 21.20 & 31.2 & 143.0 & 94.3 & 155.3 & 106.6 & 97.2 \\
\hline 201 & 12.30 & 19.0 & 34.1 & 28.7 & 38.4 & 33.0 & 30.1 \\
\hline \multicolumn{8}{|c|}{ DPLR + NEQAIR96 } \\
\hline 151 & 7.2 & NA & 6.1 & 4.0 & 13.3 & 11.2 & 10.8 \\
\hline 169 & 16.2 & NA & 43.4 & 27.0 & 59.5 & 43.2 & 40.5 \\
\hline 177 & 20.5 & NA & 61.3 & 40.2 & 81.8 & 60.7 & 56.7 \\
\hline 185 & 25.4 & NA & 83.4 & 59.2 & 108.8 & 84.6 & 78.7 \\
\hline 189 & 25.7 & 36.3 & 84.5 & 62.7 & 120.8 & 99.0 & 92.7 \\
\hline 193 & 21.9 & 31.4 & 62.2 & 48.3 & 93.6 & 79.7 & 74.9 \\
\hline 201 & 12.5 & 18.8 & 12.1 & 11.0 & 30.9 & 29.8 & 28.7 \\
\hline
\end{tabular}

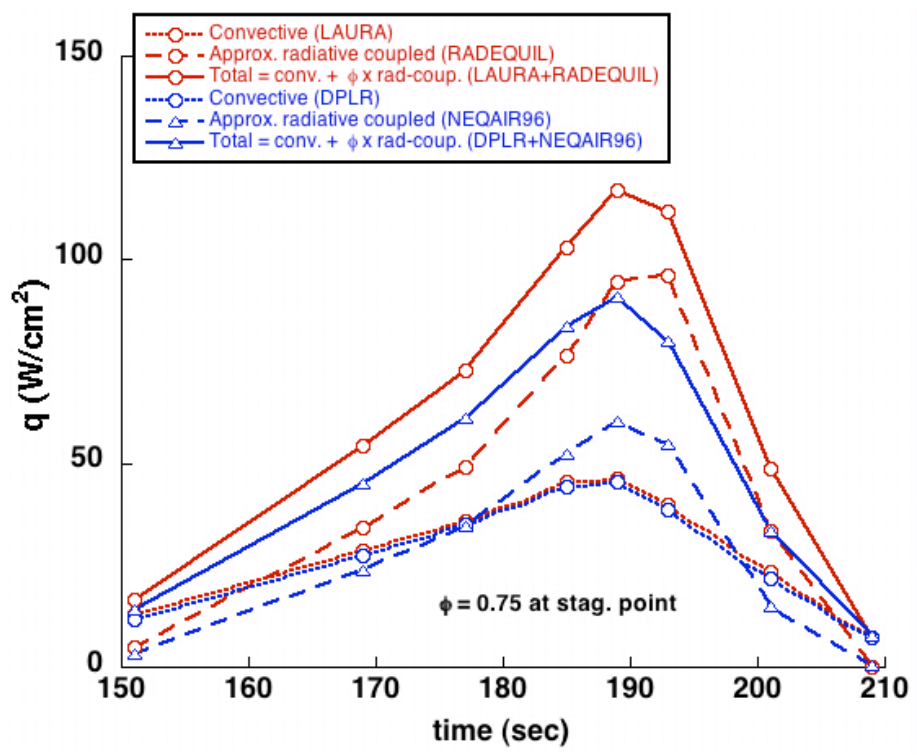

Figure 15. Heating vs. time at stagnation point

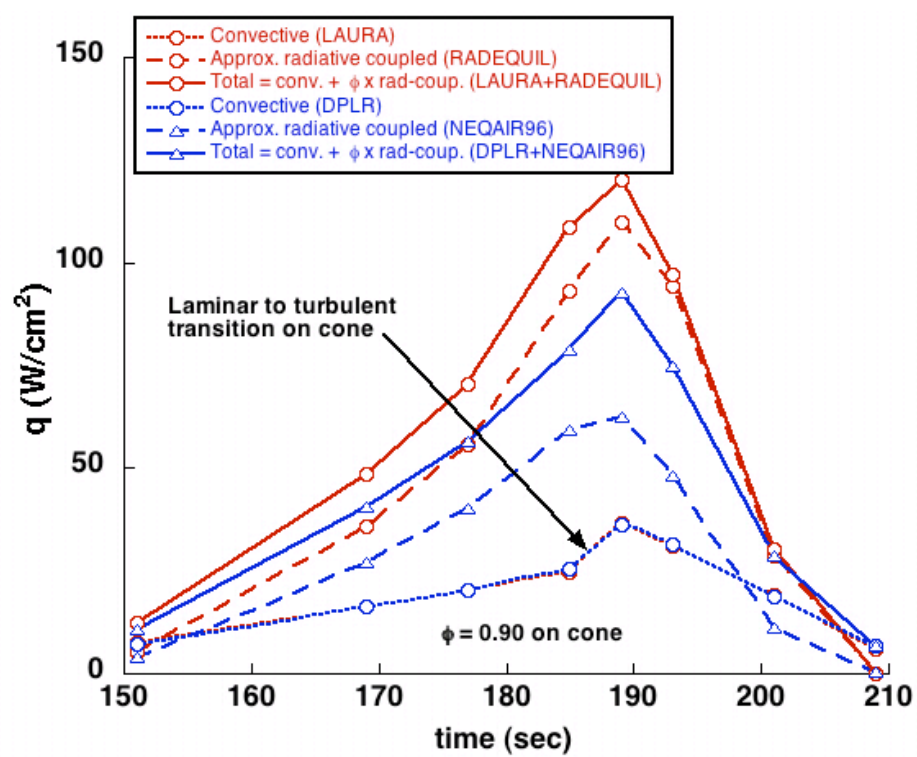

Figure 16. Heating vs. time at shoulder

\section{Summary and Conclusions}

The aerothermodynamic environment of the Huygens probe was investigated as part of an independent assessment of the Huygens mission to Titan performed under the direction of the NASA Engineering and Safety Center. Convective and radiative heating rates were computed using two independent sets of flow-field and radiation transport codes. The flow-field codes provided the convective heating rates and the input data for the radiation codes, which then were used to generate uncoupled radiative heating rates. Approximate corrections for radiation/flow-field coupling and three-dimensional effects were then applied to the uncoupled radiative rates.

Close agreement was found between convective heating predictions from the two flow-field codes, LAURA and DPLR. Larger differences (up to $40 \%$ to $60 \%$ ) were observed in the radiative heating predictions from the two radiation transport codes, RADEQUIL and NEQAIR96. It was theorized that these differences were due in part to differing amounts of radiative absorption being predicted by the two radiation transport codes, but no definite conclusions were reached within the course of the study.

Factors that influenced the predicted heating levels were examined. Both convective and radiative heating rates were found to be proportionately dependent on the amount of free stream $\mathrm{CH}_{4}$ assumed to be present in the atmosphere. It was also demonstrated that because of the disparity of molecular weights of the species present in the flow field, a multi-component diffusion model must be employed in order to obtain the correct convective heating 
levels for hypersonic flight in the atmosphere of Titan. Finally, a conservative estimate for transition onset time indicated transition would occur near peak heating; however, while transition to turbulence augmented the convective heating on the conical flank of the vehicle, the levels remained lower than those at the stagnation point.

Time-histories of the convective and radiative heating rates were generated through computations along the peak-heating trajectory identified through a Monte Carlo analysis of trajectory dispersions. These data were used in a separate thermal analysis (not discussed herein) from which it was concluded that the loads generated by the aerothermodynamic environment would be within the performance range of the thermal protection system.

\section{Acknowledgements}

Funding for this activity was provided by the NASA Engineering and Safety Center. Upgrades and modifications to the computational tools used in this study were funded in part by the NASA In-Space Propulsion program.

\section{References}

${ }^{1}$ Jaffe, L. D., and Herrell, L. M., "Cassini/Huygens Science Instruments, Spacecraft, and Mission,” Journal of Spacecraft and Rockets, Vol. 34, No. 4, July-August 1997, pp. 509-521.

${ }^{2}$ NASA Engineering and Safety Center, "Assessment of the Cassini/Huygens Probe Entry, Descent and Landing (EDL) at Titan," NESC-RP-05-67, May 2005.

${ }^{3}$ Wright, M. J., Hollis, B. R., Bose, D., and Walpot, L., "Post-Flight Aerothermal Analysis of Huygens Probe," 3rd International Planetary Probe Workshop, Anavyssos, Greece, June-July 2005.

${ }^{4}$ Justus, C. G., Duval, A., and Johnson, D. L., "Engineering-Level Model Atmospheres for Titan and Neptune," AIAA Paper 2003-4803, July 2003.

${ }^{5}$ Desai, P. N. and Cheatwood, F. M., "Entry Dispersion Analysis for the Genesis Sample Return Capsule," Journal of Spacecraft and Rockets, Vol. 38, No. 3, 2001, pp.345-350.

${ }^{6}$ Winchenbach, G. et al., "Huygens Probe Aerodynamics Free Flight Test Results: ARF Ballistic Spark Range," WL-ARO-950022 , March 1995.

${ }^{7}$ Striepe, S. A., Powell, R. W., Desai, P. N., Queen, E. M., Brauer, G. L., Cornick, D. E., Olson, D. W., Petersen, F. M., Stevenson, R., Engel, M. C., Marsh, S. M., Gromko, A. M., "Program to Optimize Simulated Trajectories (POST II), Vol. II Utilization Manual.” Version 1.1.6.G, January 2004, NASA Langley Research Center, Hampton, VA.

${ }^{8}$ Spencer, D. A., Braun, R. D., "Mars Pathfinder Atmospheric Entry - Trajectory Design and Dispersion analysis," Journal of Spacecraft and Rockets, Vol. 33, No. 5, Sept./Oct. 1996, pp. 670-676.

${ }^{9}$ Desai, P. N., Schoenenberger, M., and Cheatwood, F. M., "Mars Exploration Rover Six-Degree-Of-Freedom Entry Trajectory Analysis," AAS Paper 03-642, August 2003.

${ }^{10}$ Desai, P. N., Lyons, D. T., "Entry, Descent, and Landing Operations Analysis for the Genesis Re-Entry Capsule," AAS Paper 05-121, January 2005.

${ }^{11}$ Lockwood, M. K., "Neptune Aerocapture System Analysis," AIAA Paper 2004-4951, August 2004.

${ }^{12}$ Way, D. W., Powell, R. W., Edquist, K. T., Masciarelli, J. P., and Starr, B. P., "Aerocapture Simulation and Performance for the Titan Explorer Mission," AIAA Paper 2003-4951, July 2003.

${ }^{13}$ Lockwood, M. K., “Titan Aerocapture Systems Analysis,” AIAA Paper 2003-4799, July 2003.

${ }^{14}$ Takashima, N., Hollis, B. R., Zoby, E. V., Sutton, K., Olejniczak, J., Wright, M. J., and Prabhu, D., "Preliminary Aerothermodynamics Analysis of Titan Aerocapture Aeroshell," AIAA Paper 2003-4952, July 2003.

${ }^{15}$ Olejniczak, J., Wright, M. J., Prabhu, D., Takashima, N., Hollis, B. R., Zoby, E. V., and Sutton, K., "An Analysis of the Radiative Heating Environment for Aerocapture at Titan,” AIAA Paper 2003-4953, July 2003.

${ }^{16}$ Gnoffo, P. A., “An Upwind-Biased, Point-Implicit Algorithm for Viscous, Compressible Perfect-Gas Flows,” NASA TP-2953, Feb. 1990.

${ }^{17}$ Cheatwood, F. M., and Gnoffo, P. A., "User's Manual for the Langley Aerothermodynamic Upwind Relaxation Algorithm (LAURA)," NASA TM 4674, April 1996.

${ }^{18}$ Wright, M.J., Candler, G.V., and Bose, D., "Data-Parallel Line Relaxation Method for the Navier-Stokes Equations," AIAA Journal, Vol. 36, No. 9, 1998, pp. 1603-1609.

${ }^{19}$ Roe, P. L., "Approximate Riemann Solvers, Parameter Vectors and Difference Schemes,” Journal of Computational Physics, Vol. 43, No. 2, 1981, pp. 357-372.

${ }^{20}$ Harten, A., "High Resolution Schemes for Hyperbolic Conservation Laws," Journal of Computational Physics, Vol. 49, No. 3, 1983, pp. 357-393.

${ }^{21}$ Yee, H. C., "On Symmetric and Upwind TVD Schemes," NASA TM 88325, 1990.

${ }^{22}$ MacCormack, R.W. and Candler, G.V., "The Solution of the Navier-Stokes Equations Using Gauss-Seidel Line Relaxation," Computers and Fluids, Vol. 17, No. 1, 1989, pp. 135-150.

${ }^{23}$ Yee, H.C., "A Class of High-Resolution Explicit and Implicit Shock Capturing Methods,” NASA TM 101088, Feb. 1989.

12

American Institute of Aeronautics and Astronautics 
${ }^{24}$ Gökçen, T., "N $\mathrm{N}_{2}-\mathrm{CH}_{4}$-Ar Chemical Kinetic Model for Simulations of Atmospheric Entry to Titan," AIAA Paper 2004-2469, June-2004.

${ }^{25}$ Park, C., “Assessment of Two Temperature Kinetic Model for Ionizing Air,” AIAA Paper 1987-1574, June 1987.

${ }^{26}$ McBride, B. J., Zehe, M. J., and Gordon, S., "NASA Glenn Coefficients for Calculating Thermodynamic Properties of Individual Species," NASA TP 2002-211556, Sept. 2002.

${ }^{27}$ Nicolet, W. E., "Advanced Methods for Calculating Radiation Transport in Ablation-Product Contaminated Boundary Layers," NASA-CR-1656, Sept. 1970.

${ }^{28}$ Whiting, E. E., Yen, L., Arnold, J. O. and Paterson, J. A., "NEQAIR96, Nonequilibrium and Equilibrium Radiative Transport and Spectra Program: User's Manual,” NASA RP-1389, Dec. 1996.

${ }^{29}$ Bose, D., Wright, M. J., Bogdanoff, D. W., Raiche, G. A., and Allen, G. A., "Modeling and Experimental Validation of CN Radiation Behind a Strong Shock Wave," AIAA Paper 2005-0768, Jan. 2005

${ }^{30}$ Tauber, M., and Wakefield R., "Heating Environment and Protection During Jupiter Entry," Journal of Spacecraft and Rockets, Vol. 8, No. 3, 1971, pp. 630-636.

${ }^{31}$ Goulard, R., "The Coupling of Radiation and Convection in Detached Shock Layers," Journal of Quantitative Spectroscopy and Radiative Heat Transfer, Vol. 1, 1961, pp. 249-257.

${ }^{32}$ Wright, M. J., Bose, D., and Olejniczak, J., "Impact of Flowfield-Radiation Coupling on Aeroheating for Titan Aerocapture," Journal of Thermophysics and Heat Transfer, Vol. 19, No. 1, January-March 2005.

${ }^{33}$ Bose, D., and Wright, M. J., "View-Factor-Based Radiation Transport in a Hypersonic Shock Layer," Journal of Thermophysics and Heat Transfer, Vol. 18, No. 4, 2004, pp. 553-555.

${ }^{34}$ Sutton, K. and Gnoffo, P. A., "Multi-Component Diffusion with Application to Computational Aerothermodynamics," AIAA Paper 1998-2575, June 1998.

${ }^{35}$ Ramshaw, J. D., "Self-Consistent Effective Binary Diffusion in Multicomponent Gas Mixtures," Journal of NonEquilibrium Thermodynamics, Vol. 15, No. 3, 1990, pp. 295-300.

${ }^{36}$ Hollis, B. R, Liechty, D. S., Wright, M. J., Holden, M. S., Wadhams, T. P., MacLean, M., and Dyakonov, A., "Transition Onset and Turbulent Heating Measurements on the Mars Science Laboratory Entry Vehicle," AIAA Paper 2005-1437, Jan. 2005 